\title{
Investigating the barriers of using just in time purchasing system for publically traded firms in Tehran stock exchange
}

\author{
Ghodrat Allah Haidari nejad $^{\mathrm{a}^{*}}$, Ali Kazemi ${ }^{\mathbf{a}^{*}}$ and Reza Gholami ${ }^{\mathbf{b}}$
}

${ }^{a}$ Department of Accounting, Islamic Azad University, Ilam Branch, Ilam, Iran

${ }^{b}$ Department of Industrial Engineering, Islamic Azad University, Ilam Branch, Ilam, Iran

\begin{tabular}{|c|c|}
\hline ARTICLEINFO & A B S T R A T T \\
\hline $\begin{array}{l}\text { Article history: } \\
\text { Received October 8, } 2011 \\
\text { Received in Revised form } \\
\text { November, 18, } 2011 \\
\text { Accepted } 22 \text { November } 2011 \\
\text { Available online } \\
25 \text { November } 2011 \\
\text { Keywords: } \\
\text { JIT } \\
\text { JIT purchasing plan } \\
\text { Inventory systems } \\
\text { Tehran Stock Exchange }\end{array}$ & $\begin{array}{l}\text { Just in time is one of the most important components of having efficient production plan. The } \\
\text { primary objective of JIT is to reduce the amount of storage as much as possible to remove the } \\
\text { cost of inventories and work-in-progress. However, the implementation of JIT is a tedious task } \\
\text { especially in developing countries, where there are shortages for essential infrastructures and } \\
\text { increase the risk of production in case of JIT adaptation. In this paper, we present a survey to } \\
\text { detect important factors preventing JIT implementation in Iran. The proposed study designs a } \\
\text { questionnaire for assessing important factors influencing JIT adaptation, which includes } \\
\text { inflation, political sanction, unreliable suppliers, shortage of cash flow and weak organizational } \\
\text { culture. The results of our survey confirm that shortage of cash flow is the most important } \\
\text { factor, follows by economical sanction and inflation. }\end{array}$ \\
\hline
\end{tabular}

(C) 2012 Growing Science Ltd. All rights reserved.

\section{Introduction}

Just in time (JIT) is a cost efficient technique, which attempts to improve the return on investment by removing in-process inventory and associated carrying costs as much as possible. To reach the idea of JIT, the process uses on signals or Kanban between different points in the process, which tells production when to make the next part. JIT concentrates on continuous improvement and can improve a manufacturing organization's return on investment, quality, and productivity (Schonberger, 1982; Ansari, 1982).

Mullarkey et al. (1995) performed a two-phase investigation to study employee reactions to JIT manufacturing practices. Their results indicated that the introduction of product-based manufacturing, incorporating strong elements of total quality management (TQM) was related to different factors such as increases in employee autonomy; increases in some job demands; etc. They also reported that

* Corresponding author. Tel: +989398805733

E-mail addresses: haidari.nejad@yahoo.com (G. Hairari Nejad) 
later introduction of core JIT practices and associated layout changes were related to no change in existing levels of employee autonomy and job demands; statistically significant increases in collective autonomy over the timing of group tasks; etc. They also recommended that reductions in employee autonomy, increased production pressure and employee stress could not influence of JIT manufacturing.

Giunipero and O'Neal (1988) investigated key barriers to JIT-purchasing implementation and reported six major barriers, which are type of production process, frequency of schedule changes, lack of supplier benefits, distance from suppliers, focus on price versus cost, and lack of role models to follow.

There are several arguments that the poor supply and demand conditions, and the unstable economic environments could be the main barriers for JIT use in developing countries. There are other important factors including high costs of; imported technology, training, maintenance and the quality systems, low costs of labor and, the cultural values based on both high power distance and uncertainty avoidance.

Abdul-Nour et al. (1998) surveyed on how to overcome some of the barriers that most of small firms were facing when implementing JIT, such as lack of materials and human resources, high employees turnover, lack of influence over suppliers, etc. To remove those obstacles, a project management approach was implemented and, as we expected, productivity and quality for the case study went up, and lead-time went down from six in less than two months.

Lawrence and Lewis (1996) reported that poor supplier bases and infrastructures pose significant barriers for the implementation of just-in-time (JIT) purchasing in developing countries. They analyzed two distinct activities characteristic of JIT purchasing, which includes JIT deliveries from suppliers and supplier involvement in improvement activities in Mexican industries. The results indicated that both JIT deliveries and supplier involvement in improvement activities could enhance performance in Mexican industries under some conditions. They reported that the effectiveness of pursuing JIT deliveries relies on plant and company size and high levels of supplier involvement depends on developing a network within the parent company.

Oral et al. (2003) studied JIT implementation in Turkey and reported that inflation was not a barrier against implementation of JIT by Turkish prefabrication companies. In addition, unlike in most developing countries material supply conditions were satisfactory. The financial difficulties and the demand uncertainties were determined to be the main barriers for the implementation of JIT in the Turkish prefabrication sector.

Bayo-Moriones et al. (2008) investigated the impact of organizational context and infrastructure practices in JIT implementation. They reported an existence of diversity in different elements, which affect the use of various components of JIT and claimed that infrastructure practices were more determining than contextual factors. This occurs in particular with advanced manufacturing techniques, basic quality tools and the management of the relationships with suppliers and customers.

Matson and Matson (2007) studied the issues for the implementation of JIT among automotive suppliers in the southern USA. They identified the extent of JIT usage in Tennessee's and Alabama's 
growing automotive industry and the general elements of the companies that use JIT. They also identified the types of problems experienced by JIT automotive suppliers; periodically recurring, or ongoing; and determined the most troublesome issues. Amoako-Gyampah and Gargeya (2001) investigated the implementation of JIT in Ghana. They reported that Ghanaian manufacturing factories, which have invested in JIT systems were different from ones, which had not in terms of their efforts in employees' training, setup time reduction, cellular manufacturing, continuous quality improvement, and supplier partnership. One of the important layers for having medium benefits of JIT advantages is to use vendor manager inventory (VMI) systems. There are literally tremendous works for having good experiences of VMI implementation. In VMI, all benefits are distributed between disproportionally between buyers and suppliers. Yao et al. (2007) developed an analytical framework, which explores how important supply chain parameters influence the realized cost savings from collaborative initiatives such as vendor-managed inventory (VMI). They reported that benefits, in the form of inventory cost reductions, could be generated from integration depending upon the ratio of the order costs of the supplier to the buyer and the ratio of the carrying charges of the supplier to the buyer.

The present study surveys to detect important factors preventing JIT implementation in Iran. The proposed study designs a questionnaire for assessing important factors influencing JIT adaptation, which includes inflation, political sanction, unreliable suppliers, shortage of cash flow and weak organizational culture. The organization of this paper first explains details of the survey in section 2, the results of the survey are given in section 3 and the paper ends with concluding remarks.

\section{The proposed study}

In this paper, we look to find the impact of five important factors influencing JIT adaptation including inflation, political sanction, unreliable suppliers, shortage of cash flow and weak organizational culture. In our survey, the questions are arranged in Likert scale in five segments from completely disagree to completely agree and the likelihood is set to 0.6. Table 1 summarizes five main hypothesis of our survey.

\section{Table 1}

The summary of hypotheses

\begin{tabular}{|c|c|c|}
\hline Item & Hypothesis & \\
\hline \multirow[b]{2}{*}{1} & $H_{0}$ : Inflation has no impact on JIT adaptation. & $\int H_{0}: \quad p \leq 0.6$ \\
\hline & $H_{1}:$ Inflation has impacts JIT adaptation. & $H_{1}: \quad p>0.6$ \\
\hline \multirow{2}{*}{2} & $H_{0}$ : Economical embargo has no impact on JIT adaptation. & $\int H_{0}: p \leq 0.6$ \\
\hline & $H_{1}:$ Economical embargo impacts JIT adaptation. & $H_{1}: \quad p>0.6$ \\
\hline \multirow{2}{*}{3} & $H_{0}$ : Shortage of good supplier has no impact on JIT adaptation. & $H_{0}: \quad p \leq 0.6$ \\
\hline & $H_{1}:$ Shortage of good supplier impacts JIT adaptation. & $H_{1}: \quad p>0.6$ \\
\hline \multirow[b]{2}{*}{4} & $H_{0}$ : Shortage of good supplier has no impact on JIT adaptation. & $\int H_{0}: p \leq 0.6$ \\
\hline & $H_{1}$ : Shortage of good supplier impacts JIT adaptation. & $H_{1}: \quad p>0.6$ \\
\hline \multirow[b]{2}{*}{5} & $H_{0}$ : Lack of a good organizational culture has no impact on JIT adaptation. & $H_{0}: p \leq 0.6$ \\
\hline & $H_{1}:$ Lack of a good organizational culture impacts JIT adaptation. & $H_{1}: \quad p>0.6$ \\
\hline
\end{tabular}


The survey is executed on some publicly traded companies in Tehran Stock Exchange (TSE). Our survey indicates that there were 445 firms publicly traded in Iran during the year 2011. The number of necessary sample is calculated as follows,

$n=\frac{z_{\alpha / 2}^{2} \delta_{x}^{2}}{\varepsilon^{2}}$,

where $\delta_{x}$ is the standard deviation, $\varepsilon$ is the estimation error, $z$ is the normal distribution and $n$ is the number of sample size, respectively. In our survey, we considered $\delta_{x}=0.5, \varepsilon=0.07, \alpha=0.05$ and $z_{\alpha / 1}=0.05$, which yields $n=196$. Therefore we perform the survey for 196 firms in our survey.

\section{Results}

In this section, we present details of our survey for five hypotheses using binomial test. Table 2 shows details of our survey.

\section{Table 2}

Details of the results of survey for five hypothesis

\begin{tabular}{lcccc}
\hline Hypothesis & & Numbers & Ratio & Significance level \\
\hline \multirow{2}{*}{ The impact of inflation } & $p>0.60$ & 155 & 0.92 & \multirow{2}{*}{0.000} \\
The impact of economical embargo & $p \leq 0.60$ & 13 & 0.08 & 0.000 \\
& $p>0.60$ & 148 & 0.88 & \\
The lack of good supplier & $p \leq 0.60$ & 20 & 0.12 & 0.000 \\
The shortage of cash flow & $p>0.60$ & 159 & 0.95 & \multirow{2}{*}{0.000} \\
The shortage of a good organizational culture & $p \leq 0.60$ & 9 & 0.05 & \\
& $p>0.60$ & 162 & 0.96 & 0.000 \\
\hline
\end{tabular}

As we can observe from the results of Table 2, all null hypothesis are rejected leaving us to conclude that all five items influence the JIT implementation, significantly. However, we need to use Freedman test to rank these factors and the results are shown in Table 3.

\section{Table 3}

The results of Freedman test

\begin{tabular}{ccccc}
\hline Statistical value & Degree of freedom & Significance level & Confidence level & Null hypothesis \\
\hline 70.938 & 4 & 0.000 & 0.05 & Reject \\
\hline
\end{tabular}

As we can observe the null hypothesis is reject in favor of an alternative hypothesis, which means that we can use freedman test to rank five alternatives. Fig. 1 shows details of the ranking of alternatives. 


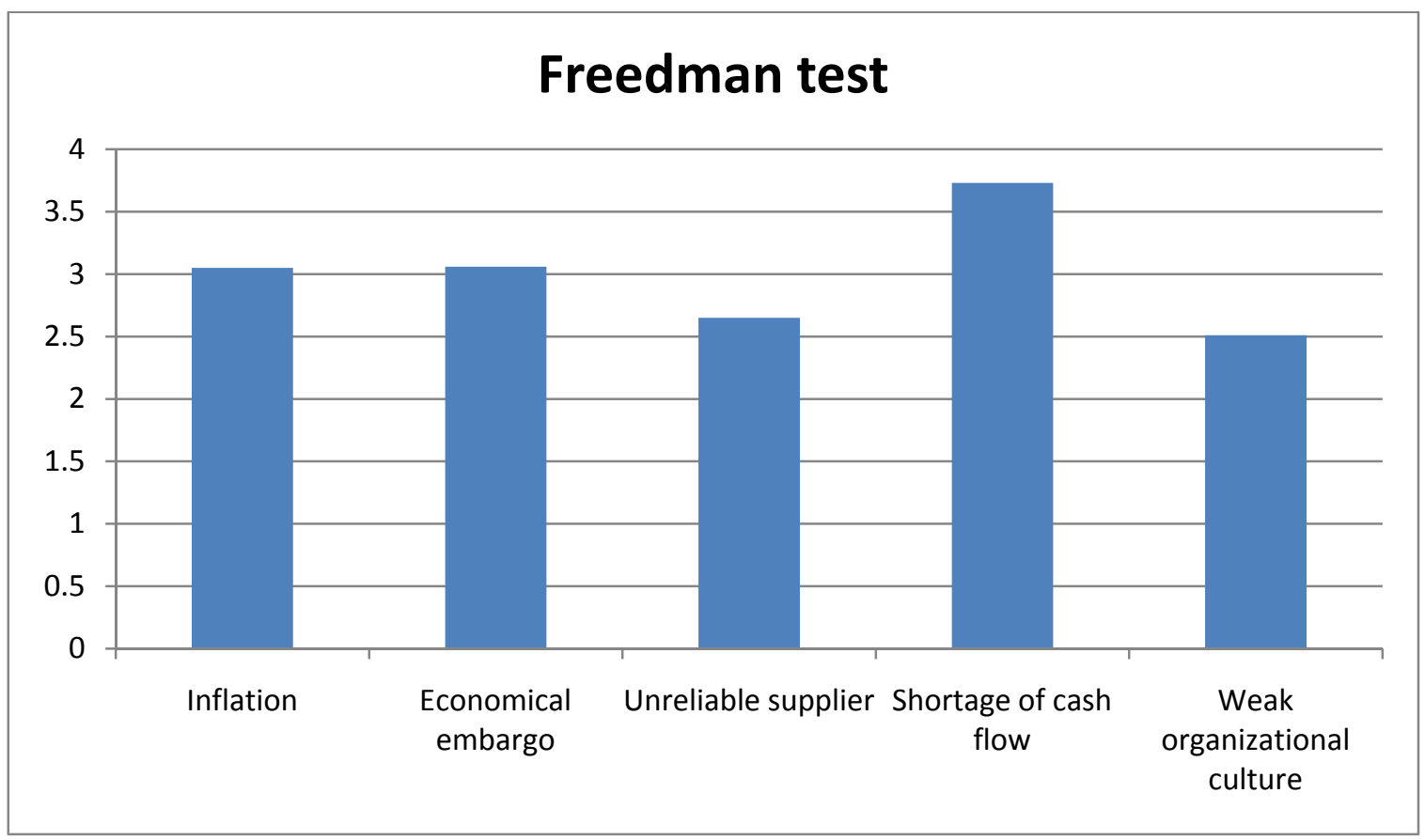

Fig. 1. Freedman test results for five hypotheses

As we can observe from the freedman test results for ranking different hypothesis, shortage of cash flow (3.74) is blamed the most important item followed by inflation (3.06) and economical embargo (3.05), unreliable supplier (2.65) and weak organizational culture (2.51). On important observation is that the current political uncertainty could motivate business managers to prefer to have a big inventory just to make sure that they would not face with shortage on raw materials. This could absorb significant amount of money, which yields shortage of cash flow. Therefore, any shortage on cash flow could be indirectly influenced by other uncertainties surrounding the economy.

\section{Conclusion}

In this paper, we have presented an empirical study to determine the most important factors influencing adaptation of JIT in publicly held firms in Iran. The proposed study of this research has chosen 196 firms out of 445 companies whose shares were traded in Tehran stock exchange. The results of our survey indicated that shortage of cash flow is the most important items for having JIT adaptation, followed by inflation and economical embargo, unreliable supplier and weak organizational culture. We have concluded that the existence of uncertainty in current economy of Iran could be an indirect reason for having shortage of cash flow since people prefer to use a big chunk of their current assets for holding unnecessary raw materials, As a result, we may expect shortage of money.

\section{Acknowledgement}

The authors would like to thank the anonymous referees for their comments, which has improved the quality of this paper. 


\section{References}

Abdul-Nour, G., Lambert, S., \& Drolet, J. (1998). Adaptation of JIT philosophy and Kanban technique to a small-sized manufacturing firm; a project management approach. Computers \& Industrial Engineering, 35(3-4), 419-422.

Amoako-Gyampah, K., \& Gargeya, V.B. (2001). Just-in-time manufacturing in Ghana. Industrial Management \& Data Systems, 101(3), 31-35.

Ansari, A. (1986). Survey identifies critical factors in successful implementation of just-in-time purchasing techniques. Industrial Engineering, 18 (10), 44-50.

Bayo-Moriones, A., Bello-Pintado, A., \& Merino-Díaz-de-Cerio, J. (2008). The role of organizational context and infrastructure practices in JIT implementation. International Journal of Operations \& Production Management, 28(11), 1042-1066.

Giunipero, L.C., \& O'Neal, C. (1988).Obstacles to JIT procurement. Industrial Marketing Management, 17(1), 35-41.

Lawrence, J.J., \& Lewis, H.S. (1996). Understanding the use of just-in-time purchasing in a developing country: The case of Mexico. International Journal of Operations \& Production Management, 16(6), 68-90.

Matson, J.E., \& Matson, J. O. (2007). Just-in-time implementation issues among automotive suppliers in the southern USA. Supply Chain Management: An International Journal, 12(6), 432-443.

Mullarkey, S., Jackson, P.R., \& Parker, S.K. (1995). Employee reactions to JIT manufacturing practices: a two-phase investigation. International Journal of Operations \& Production Management, 15(11), 62-79.

Oral, E.L., Mistıkoglu, G., \& Erdis, E. (2003). JIT in developing countries-a case study of the Turkish prefabrication sector. Building and Environment, 38(6), 853-860.

Yao, Y., Evers, P. T., \& Dresner, M. E. ( 2007). Supply chain integration in vendor-managed inventory. Decision Support Systems, 43(2), 663-674.

Schonberger, R. J. (1982). Japanese Manufacturing Techniques: Nine Hidden Lessons in Simplicity. Free Press, ISBN 0-02-929100-3. 